УДК 81'42

ББК 81

DOI: https://doi.org/10.17308/lic.2020.3/2935

\title{
ИССЛЕДОВАТЕЛЬСКИЙ ДИСКУРС: ЖАНРОВЫЕ УНИВЕРСАЛИИ И ДИСЦИПЛИНАРНАЯ СПЕЦИФИКА НАУЧНЫХ СТАТЕЙ
}

\author{
Е. В. Вахтерова, О. О. Борискина \\ Воронежский государственный университет
}

А. О. Стеблецова

Воронежский государственный медицинский университет имени Н. Н. Бурденко

\section{RESEARCH DISCOURSE: GENRE UNIVERSALS AND DISCIPLINARY SPECIFICS OF RESEARCH PAPERS}

\author{
E. V. Vakhterova, O. O. Boriskina \\ Voronezh State University \\ A. O. Stebletsova \\ Voronezh N. N. Burdenko State Medical University
}

\begin{abstract}
Аннотация: работа посвящена изучению академического исследовательского дискурса. Целью данного исследования является определение исследовательского дискурса как типа академического, а также выявление и анализ общих жанровых черт и дисциилинарной вариативности англоязычной исследовательской статьи. Рассматриваются англоязычные исследовательские статьи медицинских и лингвистических журналов. Авторы приходят к заключению, что исследовательская статья является ядром исследовательского дискурса; макроструктура исследовательской статьи является универсальной характеристикой англоязычного исследовательского дискурса; выявлены ряд специфических характеристик медицинских и лингвистических статей, отражающих дисииплинарную вариативность исследовательского дискурса.

Ключевые слова: академический дискурс, исследовательский дискурс, англоязычная исследовательская статья, жанровые универсалии, дисциилинарная вариативность, медицинская статья, лингвистическая статья.
\end{abstract}

\begin{abstract}
The authors claim that research discourse is a specific type of an academic one. The purpose of this study is to identify and analyze genre universal features and disciplinary variation of English research article. The research material is English-language research papers from medical and linguistic scientific journals. The results demonstrate that research paper is the core of research discourse; the macrostructure of a research article is a universal characteristic of an English-language research discourse; a number of specific characteristics of research discourse have been identified.

Key words: academic discourse, research discourse, English research article, genre universals, disciplinary variation, medical article, linguistic article.
\end{abstract}

\section{Введение}

На рубеже XX-XXI вв. понятие академический дискурс прочно вошло в обиход лингвистических исследований. Если еще в 70-80-е гг. прошлого столетия оно устойчиво ассоциировалось с методическими направлениями или прикладной лингвистикой

(C) Вахтерова Е. В., Борискина О. О., Стеблецова А. О., 2020 
(английский для специальных целей (ESP) и английский для академических целей (EAP)) [1-3], то в последние десятилетия академический дискурс все чаще становится объектом дискурсологии и жанрового анализа [4-7], корпусной лингвистики [8; 9] и контрастивных исследований [10-12].

Нынешний интерес к письменному модусу академического дискурса в значительной степени является результатом некоторых важных событий последних двадцати лет: масштабные изменения в высшем образовании в Европе и России, которые повлекли за собой повышение значимости письменных аспектов академической коммуникации и усиление роли английского языка как международного языка научных исследований.

Академический дискурс в широком смысле относится к способам мышления и использования языка в сфере науки и образования [6]. Понимая академический дискурс как когнитивно-коммуникативную деятельность [13; 14], естественно представить его в виде компонентов и продуктов этой деятельности. Учебники и монографии, доклады и лекции, обзоры и научные статьи являются дискурсивными событиями академической сферы, под которыми мы понимаем законченные фрагменты дискурса, объединенные общей темой, участниками и дискурсивными действиями [15]. В ходе дискурсивных событий создаются продукты дискурсивной деятельности одноименные тексты, отражающие письменный модус дискурса [15]. Таким образом, дискурсивные события, их участники и продукты-тексты являются составными частями объемного и многомерного феномена - академического дискурса.

Определение академический в отношении коммуникации, дискурса, текста, выходящее из англоязычной терминологической традиции, во многом синонимично определению научный дискурс, текст, стиль, используемый в отечественных лингвистических и филологических дисциплинах. Наш терминологический выбор в пользу академического дискурса обусловлен англоязычным материалом исследования, а также стремлением к единообразию терминологического аппарата.

Академический дискурс требует глубокого исследования особенно теперь, когда подавляющее большинство научных публикаций выходит на английском языке, являющемся неродным для большинства авторов. Актуальность изучения академического дискурса значима и для русскоязычных авторов, поскольку публикационный доступ к англоязычному научному дискурсу тесно связан с академической компетентностью или грамотностью, т. е. знанием жанровых характеристик англоязычного академического дискурса и умением адаптировать к ним свой научный материал. Ведь английский как lingua franca между- народной науки диктует прагматические, лингвостилистические и жанровые нормы академического дискурса, которым следуют его участники во всем мире [16]. Знание этих норм является условием успешного участия в международном академическом сообществе.

Изучение академического дискурса возможно и целесообразно в аспекте жанрового подхода. Жанровый и дискурсивный анализ имеют точки пересечения относительно понимания места и структуры текста, а также неизбежные параллели между понятиями типа дискурса и жанра речи, дискурсивного события и коммуникативного события [15; 17$]$.

Если понимать под жанром нормативное и стандартизованное коммуникативное событие, описываемое в терминах коммуникативной цели [18; 19], то этот подход вполне применим для исследования академического дискурса и его письменного модуса. Понятие дискурсивного жанра как устойчивого сочетания дискурсивного действия с определенным типом текста уже использовалось в сопоставительных исследованиях делового дискурса [15]. Последовательный сторонник использования жанрового подхода при изучении академического дискурса К. Хайленд утверждает, что жанровый анализ можно рассматривать как более специфичный вид дискурсивного анализа, нацеленный на исследование любых компонентов языка и речи [20]. Поэтому при работе с текстами исследовательских статей, являющихся образцами письменного модуса академического дискурса, представляется целесообразным использование жанрового подхода, поскольку исследовательская статья - это одновременно и жанр, и продукт академического дискурса.

Академический дискурс: основные характеристики и кониееция жанровой вариативности

Изучение академического дискурса в русле англосаксонской традиции предполагает выделение общих или универсальных черт, раскрывающих его концептуальные, функционально-прагматические, жанрово-стилистические и прочие характеристики. Основываясь на работах Дж. Свэйлза [5], В. Бхатия [4], Дж. Флауэрдью [21], К. Хайланда [6], представим эти характеристики в виде следующих положений.

1. Академический дискурс является выражением науки и научной деятельности. При всем дисциплинарном и жанровом разнообразии его письменного модуса именно наука является тем социальным конструктом, который прямо или опосредованно отражается в дискурсивных событиях и академических текстах.

2. Академический дискурс характеризуется двойной коммуникативной функцией: информативной, 
т. е. представляющей новые знания, и персуазивной, призванной одновременно убедить читателя в достоверности своих выводов.

3. Академический дискурс располагает собственным лингвостилистическим, жанровым, риторическим репертуаром средств и приемов для реализации своего содержательного и функционального потенциала вне зависимости от конкретной научной дисциплины.

В то же время появляются данные о дискурсивных различиях, обнаруживаемых в академическом стиле разных научных дисциплин [22-24]. Исследователи обнаруживают расхождения в структурной организации магистерских и докторских диссертаций в различных научных дисциплинах $[25 ; 26]$, анализируют отличительные особенности секции Meтоды в статьях разных научных отраслей [27], выявляют национально-культурную специфику дискурса [28-30]. Результаты этих исследований послужили своеобразным толчком для возникновения концепции дисицплинарной вариативности, разработанной К. Хайландом $[6 ; 20 ; 31]$. Согласно этой концепции, академический дискурс неоднороден: разные науки по-разному конструируют знание и используют разные способы его трансляции; тексты разных научных отраслей знания могут существенно различаться в выборе языковых средств, приемов аргументации, в традициях цитирования, самоцитирования и способах выражения авторской позиции. Иными словами, именно дисииплинарная вариативность академического дискурса обусловливает жанровое и языковое своеобразие академических текстов разных научных дисциплин [31].

Именно концепция дисциплинарной вариативности академического дискурса послужила отправной точкой выделения и изучения одной из его разновидностей - исследовательского дискурса, представленного в виде исследовательской статьи в разных науках, с целью выявления его жанровых универсалий. Понятие исследовательский дискурс должно соответствовать такому типу академического дискурса, который отражает продукты речевого взаимодействия, включенного в собственно исследовательскую деятельность. Так, устный модус исследовательского дискурса включает в себя всю коммуникативную деятельность как во время проведения исследования, так и вокруг него. Письменный модус фиксирует исследование в ряде текстов: от исследовательской заявки (Research Proposal) до диссертации (Thesis).

\section{Материалы и методы}

Цель настоящей работы состоит в выявлении жанровых универсалий в рамках дисциплинарной вариативности англоязычной исследовательской статьи как основного жанра исследовательского дискурса.

Достижение данной цели включало следующие этапы исследования:

1) сбор эмпирического материала;

2) определение критериев и процедуры анализа;

3) сопоставление материала по выделенным критериям;

4) интерпретация полученных в ходе сопоставления данных;

5) определение универсальной жанровой структуры исследовательской статьи.

Выбор исследовательской статьи в качестве материала исследования обусловлен ее структурно-функциональными характеристиками: постановка исследовательской проблемы или гипотезы, выбор материала и методов, объекта и предмета исследования, хода и результатов, т. е. всех тех категорий и стадий, которые и составляют дискурсивную деятельность ученого. В качестве разных научных дисциплин были избраны медицина и лингвистика. Поскольку лингвистика относится к гуманитарным наукам или soft sciences, а медицина - к естественным или hard sciences, то именно анализ статей этих научных сфер потенциально способен обнаружить жанровые универсалии и дисциплинарную вариативность англоязычного исследовательского дискурса. Безусловно, международные научные журналы предъявляют собственные требования к структурно-содержательным разделам статей, которые обусловлены как нормами различных международных баз данных и индексов цитирования, так и спецификой исследований в различных дисциплинах, что не снижает значимости структурно-функциональных характеристик исследовательской статьи как жанра академического дискурса.

Материалом исследования послужили 15 англоязычных лингвистических исследовательских статей из журналов «Applied Linguistics», «Applied Linguistics Research Journal» и «Discourse Studies» за 20182019 гг. и 15 англоязычных медицинских исследовательских статей из журналов «British Medical Journal» и «New England Journal of Medicine» за 2018-2019 гг. Общий объем проанализированного материала составил 223000 слов.

В данном исследовании были использованы методы количественного, дескриптивного (описательного) анализа и сопоставительного анализа. Исследование выполнялось в русле дискурсивного анализа с применением формально-структурных, жанрово-стилистических и содержательных категорий дискурса [32].

Методика исследования состояла в следующем. На основании содержания научного журнала медицинской или лингвистической направленности были 
выделены жанры научных статей. Сопоставительный анализ позволил определить универсальные и дисциплинарно-специфичные жанры медицинских (МС) и лингвистических (ЛС) статей. Названия жанров статей приведены на языке оригинала во избежание неточностей, русское толкование предложено в скобках.

Затем была проанализирована макроструктура исследовательской статьи в целом, а именно был проведен количественный анализ наличия/отсутствия структурных компонентов (разделов); дескриптивно-сопоставительный анализ разделов МС и ЛС. Мы обнаружили пересекающиеся (универсальные) и дисциплинарно-вариативные разделы и сделали предварительные выводы. Также была рассмотрена семантическая структура отдельных компонентов МС и ЛС.

За рамками настоящей статьи остались затекстовые разделы ЛС и МС, а именно аннотация, ключевые слова, приложения. Исследовательская релевантность данных текстов не подлежит сомнению, они входят в общий эмпирический корпус исследования и составят предмет отдельной статьи в русле нашей работы.

\section{Результаты и обсуждение}

\section{Жанры исследовательского дискурса}

После изучения содержания выбранных нами журналов (Table of Contents) можно заключить, что исследовательский дискурс в медицинских жсурналах представлен следующими жанрами.

1. Research paper/article (исследовательская статья) - это наиболее распространенный базовый жанр, который манифестирует ход и результаты научных исследований. Дискурсивная (когнитивная) сущность научной статьи вообще заключается в установлении референции между научным открытием (результатом) и положением дел в реальности, т. е. той ее сферой, которою исследует данная дисциплина. Исследовательская статья всегда основана на оригинальном исследовании. Ее коммуникативная цель - представить результаты исследования дискурсивному сообществу. В риторическом аспекте исследовательская статья выполняет обобщенные функции описания и рассуждения, каждая из которых содержит целый спектр риторических приемов от дефиниций и иллюстраций до аргументации, комментирования и убеждения.

2. Research news (актуальные новости в области научных исследований) - небольшие по объему тексты, коммуникативная цель которых состоит в информировании дискурсивного сообщества о новейших достижениях или значимых событиях в сфере науки. Этот жанр медицинских статей находится на стыке собственно научного и научно-популярного дискурсов, так как использует публицистические выразительные средства и может быть адресован более широкой (не экспертной) аудитории.

3. Editorial (передовая статья) - это статья, открывающая журнал и выражающая мнение редакции или издателя по каким-либо важным вопросам, как правило, имеющим прикладной или социально-значимый характер.

4. Clinical Problem Solving / Clinical Case Report (отчет о клиническом случае) - типичный жанр научного медицинского дискурса. Представляет собой меньший по сравнению с исследовательской статьей текст с подробным описанием интересного клинического случая. В прагматическом смысле этот жанр используется для презентации отдельного события (клинического случая), которое может быть или не быть частью исследования, однако оно представляет существенный интерес для дискурсивного сообщества. Жанр клинического обзора характеризуется четкой макроструктурой, содержащей разделы о персональных медицинских и биологических данных пациента, о диагнозе, симптомах, признаках его заболевания, тактике и методах лечения и его результатах. В риторическом аспекте особенностью этого жанра является использование повествовательных приемов (своего рода медицинский нарратив) при представлении течения заболевания.

5. Clinical Implication of Basic Research (клиническое значение фундаментальных исследований) жанр научного медицинского дискурса, публикуемый в журнале «New England Journal of Medicine». Эта короткая статья освещает недавние открытия фундаментальной науки и обсуждает, как эти открытия могут повлиять на медицинскую практику.

6. Research Review (обзорная статья) - это жанр научной статьи, которая обобщает современное состояние понимания определенной темы, анализирует, сопоставляет и обобщает ранее опубликованные исследования по проблеме. Дискурсивно-когнитивная сущность обзорной статьи состоит в установлении референтных связей между научными концепциями, теориями, результатами исследований. Обзорная статья - это своего рода мета-анализ, исследование второго уровня, что подразумевает высокую степень обобщений, оценок и выводов. Коммуникативная цель обзорной статьи - представить полное заключение по проблеме дискурсивному сообществу. В риторическом аспекте обзорная статья выполняет функции описания (descriptive writing) и рассуждения (critical writing) с преобладанием последней и определенным набором риторических приемов, среди которых значительную роль играет сравнение.

Исследовательский дискурс в лингвистических жсрналах представлен следующими жанрами:

1) Research article (исследовательская статья); 
2) Review article (обзорная статья);

3) Book review (рецензия на книгу) - это жанр, представляющий собой обзор недавно опубликованного научного труда, монографии, коллективной монографии, сборника фундаментальных статей по значимой научной проблеме. Коммуникативной целью данного жанра является информирование дискурсивного сообщества о содержании книги, ее актуальности и значимости. Риторические особенности этого жанра заключаются в использовании рационально-оценочных приемов.

Сравнительный анализ медицинских и лингвистических жанров исследовательского дискурса показывает, что исследовательская статья и обзорная статья, представленные в обоих дискурсах, можно считать универсальными (типологическими) жанрами исследовательского дискурса. Медицинский исследовательский дискурс обнаружил большее жанровое разнообразие (research paper, research news, editorial, clinical problem solving, clinical implication of basic research, research review), что явно указывает на дисциплинарную вариативность в данном аспекте и может быть обусловлено большим количеством и разнообразием типов медицинских исследований и более тесной связью медицинской науки и практики здравоохранения.

Среди универсальных жанров исследовательского дискурса именно исследовательская статья, манифестирующая ход и результаты исследования, является ядерным жанром исследовательского дискурса. Далее будут рассмотрены ключевые параметры лингвистических и медицинских исследовательских статей.

\section{Макроструктура исследовательской статьи}

Под макроструктурой исследовательской статьи мы понимаем композиционно-содержательную организацию ее основной части, той, что в англоязычной традиции принято называть body of the text. Макроструктура исследовательской статьи представлена следующими частями.

1. Заголовок (Title).

2. Введение (Introduction).

3. Методы (Methods/Methodology).

4. Результаты (Results/Findings).

5. Обсуждение (Discussion).

6. Заключение (Conclusion).

Структурное выделение данных разделов в проанализированных нами статьях представлено в табл. 1, 2 .

Т а блли ц а 1

Макроструктура медииинских исследовательских статей (МС)

\begin{tabular}{|l|c|c|c|c|c|c|c|c|c|c|c|c|c|c|c|}
\hline \multicolumn{1}{|c|}{ Раздел } & Статья 1 & Ст. 2 & Ст. 3 & Ст. 4 & Ст. 5 & Ст. 6 & Ст. 7 & Ст. 8 & Ст. 9 & Ст. 10 & Ст. 11 & Ст. 12 & Ст. 13 & Ст. 14 & Ст. 15 \\
\hline Title & + & + & + & + & + & + & + & + & + & + & + & + & + & + & + \\
\hline Introduction & + & + & + & + & + & + & + & + & + & + & + & + & + & + & + \\
\hline Methods & + & + & + & + & + & + & + & + & + & + & + & + & + & + & + \\
\hline Results & + & + & + & + & + & + & + & + & + & + & + & + & + & + & + \\
\hline Discussion & + & + & + & + & + & + & + & + & + & + & + & + & + & + & + \\
\hline Conclusion & - & + & + & + & - & + & + & + & + & + & - & - & - & - & + \\
\hline
\end{tabular}

Та б ли ц а 2

Макроструктура лингвистических исследовательских статей (ЛС)

\begin{tabular}{|l|c|c|c|c|c|c|c|c|c|c|c|c|c|c|c|}
\hline \multicolumn{1}{|c|}{ Раздел } & Статья 1 & Ст. 2 & Ст. 3 & Ст. 4 & Ст. 5 & Ст. 6 & Ст. 7 & Ст. 8 & Ст. 9 & Ст. 10 & Ст. 11 & Ст. 12 & Ст. 13 & Ст. 14 & Ст. 15 \\
\hline Title & + & + & + & + & + & + & + & + & + & + & + & + & + & + & + \\
\hline Introduction & + & + & + & + & + & + & + & + & + & + & + & + & + & + & + \\
\hline Methods & - & + & + & + & + & + & + & + & + & + & + & + & + & + & + \\
\hline Results & + & + & & + & + & + & + & + & + & + & + & + & + & + & + \\
\hline Discussion & - & + & + & & - & & & - & + & + & & + & & - & + \\
\hline Conclusion & + & + & + & + & + & + & + & + & + & - & + & + & + & + & + \\
\hline
\end{tabular}

Заголовок (Title) является обязательным элементом текста англоязычной исследовательской статьи. Размер заголовков может варьироваться; в проанализированных нами примерах видно, что заголовки медицинских англоязычных исследовательских статей объемнее лингвистических и состоят в среднем из 18-22 слов, в то время как лингвистические из
11-15. Также для медицинских заголовков более характерно частое использование многокомпонентных словосочетаний или noun phrases, чем для лингвистических. Интересным отличием медицинских заголовков от лингвистических является наличие наименования типа исследования [33], которое часто указывается после двоеточия, тогда как в лингвистических 
статьях они могут отсутствовать. Приведем примеры заголовков:

Association between intake of non-sugar sweeteners and health outcomes: systematic review and metaanalyses of randomised and non-randomised controlled trials and observational studies (медицинская статья из журнала "British Medical Journal").

A Multifaceted Approach to the Translation of Collocations from English to Persian (лингвистическая статья из журнала “Applied Linguistics Research Journal").

Раздел Введение начинается с предоставления основной информации по определенной теме и затем сужается до конкретного вопроса исследования, касающегося этой темы. Данный раздел присутствовал во всех проанализированных нами статьях.

Раздел Mетоды описывает сам процесс исследования и дает четкое и краткое описание процедур, которые были выполнены (информация о плане исследования, характеристика выборки испытуемых, информация о внешних условиях, времени проведения исследования и т. д.). В медицинских статьях этот раздел часто детализируется отдельными подразделами и подзаголовками, например: Participants and setting, Randomisation and masking, Interventions, Procedures, Outcomes, Statictical analysis. В лингвистических статьях раздел Meтоды обязательно присутствует, он может быть озаглавлен как Methodology, Data. Важно отметить, что в лингвистических статьях названия разделов могут быть описательными (дескриптивными), что также является примером дисциплинарной вариативности.

Раздел Результаты репрезентирует собственно результаты, т. е. фактические данные, полученные в ходе исследования. Этот раздел в медицинских исследовательских статьях всегда выделяется как самостоятельный, в то время как в лингвистических статьях его могут объединять с разделом Обсуждение. Это обусловлено тем, что в МС результаты - это часто цифровые, статистические и прочие показатели, которые вполне возможно и даже необходимо представить в чистом виде, например:
For women of the same age, the corresponding differences in BMI were $1.77 \mathrm{~kg} / \mathrm{m}^{2}\left(1.56\right.$ to $\left.1.97 \mathrm{~kg} / \mathrm{m}^{2}\right)$ and $2.58 \mathrm{~kg} / \mathrm{m}^{2}$ (2.36 to $\left.2.80 \mathrm{~kg} / \mathrm{m}^{2}\right)$.

Adjusted all cause mortality at 30 days was $5.2 \%$ for patients admitted to hospitals in the highest quarter and $6.4 \%$ for patients admitted to hospitals in the lowest quarter (table 3 ; odds ratio $0.78,95 \%$ confidence interval 0.50 to $1.22 ; \mathrm{P}=0.28)$.

(BMJ 2019; 366 doi: https://doi.org/10.1136/bmj.l4416)

В ЛС результаты исследования зачастую трудно отделить от интерпретации, поскольку именно объяснение тех или иных фактов языка и речи становится результатом лингвистического исследования, например:

We can see from the move-map snippets that P12's approach moves in this instance look quite different from the pattern described above (курсив наш. - E. В., О. Б., A. C.); using P12, the offender uses the Initiating sexual topics move only after a fairly long period of Rapport building.

Neither of these texts suggests that there are any doubts or that alternative interpretations of the 'facts' would be possible. There is no mention of the writer as $I$ or we. They are also quite different from Extracts $1 \mathrm{a}-\mathrm{b}$ in their absence of past tense action verbs and passives.

(Applied Linguistics https://doi.org/10.1093/applin/amy005)

Данная разница в презентации результатов является ярким проявлением дисциплинарной вариативности исследовательских статей.

Универсальной характеристикой раздела Резульmambl является наличие визуально-графических средств репрезентации результатов. В МС это обязательный компонент, который в основном представлен в виде рисунков и таблиц. В ЛС графические средства могут либо отсутствовать, либо быть представлены преимущественно таблицами. Количественные показатели использования визуально-графических средств в текстах МС и ЛС представлены в табл. 3, 4.

Т а бли ц а 3

Использование графических средств в МС

\begin{tabular}{|c|c|c|c|c|c|c|c|c|c|c|c|c|c|c|c|}
\hline Статья & 1 & 2 & 3 & 4 & 5 & 6 & 7 & 8 & 9 & 10 & 11 & 12 & 13 & 14 & 15 \\
\hline Таблица & 1 & 4 & 3 & 3 & 1 & 5 & 3 & 0 & 3 & 2 & 3 & 1 & 2 & 2 & 3 \\
\hline Рисунок & 8 & 6 & 4 & 4 & 7 & 3 & 3 & 3 & 2 & 5 & 2 & 2 & 2 & 3 & 2 \\
\hline
\end{tabular}

Т а б л и ц а 4

Использование графических средств в ЛС

\begin{tabular}{|c|c|c|c|c|c|c|c|c|c|c|c|c|c|c|c|}
\hline Статья & 1 & 2 & 3 & 4 & 5 & 6 & 7 & 8 & 9 & 10 & 11 & 12 & 13 & 14 & 15 \\
\hline Таблица & 2 & 3 & 2 & 4 & 5 & 5 & 5 & 13 & 0 & 11 & 1 & 0 & 0 & 1 & 0 \\
\hline Рисунок & 4 & 0 & 0 & 0 & 0 & 1 & 0 & 0 & 0 & 0 & 0 & 0 & 0 & 0 & 0 \\
\hline
\end{tabular}


Использование рисунков и таблиц в МС, на наш взгляд, можно объяснить спецификой исследования: презентация результатов обследований пациентов, диагностика, объемное количество данных. В ЛС преобладают таблицы, в основном содержащие количественный анализ либо сравнительный анализ примеров.

Раздел Обсуждение, как следует из названия, комментирует, интерпретирует и предлагает авторские объяснения полученных результатов. Как уже указывалось выше, в ЛС этот раздел иногда трудно отделить от результатов. Однако в МС презентация результатов и их интерпретация в разделе Обсуждение являются принципиально самостоятельными частями статьи. Именно в разделе Обсуждение в МС авторы предлагают свое толкование полученным данным, что эксплицируется лексикой соответствующей семантики, например: our data suggest..., out results also confirm the adverse association ..., we found protective association... Таким образом, композиционно-семантическая обособленность или единство разделов Результатьл и Обсуждение можно считать еще одним проявлением дисциплинарной вариативности МС и ЛС.

Раздел Заключение или Выводы в исследовательских статьях завершает основный текст статьи, в сжатом виде обобщает основные итоги исследования. В МС он отличается небольшим объемом, иногда представлен одним-двумя абзацами. В ЛС в зависимости от общего объема текста раздел Заключение может быть более значительным, представляющим резюме теоретических и практических результатов, например:

This confirms our theory (курсив наш) that each of these situational features contributes to a rounded characterization of writing situations.

By bringing together multiple situational perspectives to interpret the dimensions, we have been able to present an integrated picture (курсив наи) (Figure 9) that makes sense of the dimensions in relation to the academic situations of the texts and thus lends itself more easily than previous single-perspective interpretations to further research and teaching applications.

(Applied Linguistics

https://doi.org/10.1093/applin/amy005)

Универсальной характеристикой раздела Заключение является экспликация необходимости дальнейших исследований в рассматриваемой проблеме. Сравним фрагменты из Заключения МС и ЛС:

(MC) Additional research is needed to investigate (курсив наш) whether developing strategies to improve the clinical expertise of low volume clinicians, triage and transfer of select high risk patient subgroups, and use of PERTs might lead to better patient outcomes.
(ЛС) These notes on stance and density illustrate how this new MD analysis can inform further investigation of clusters (курсив наш) of linguistic features in student writing.

Сравнительный анализ медицинских и лингвистических исследовательских статей показывает, что данный жанр обладает рядом универсальных (макроструктура исследовательской статьи: заголовок, введение, методы, результаты, обсуждение, заключение) и дисциплинарно-вариативных (более объемные заголовки с указанием типа исследования; наличие описательных заголовков в ЛС; объединение некоторых разделов в ЛС; большее использование графических средств в МС) параметров.

\section{Заключение}

В ходе настоящего исследования была предпринята попытка определить исследовательский дискурс как специализированный тип академического дискурca, отражающий собственно исследовательскую деятельность. Основным жанром исследовательского дискурса является исследовательская статья, которая в стандартизированном виде отражает ход и результаты исследования, представляя собой письменный модус дискурса. Являясь наиболее распространенным жанром, исследовательская статья является ядром исследовательского дискурса, поскольку функционирует в любых дисциплинах по сходным дискурсивным и лингвостилистическим нормам.

Проведенный дескриптивно-сопоставительный анализ англоязычных медицинских (МС) и лингвистических исследовательских статей (ЛС) позволил выявить ряд универсальных и специфических характеристик исследовательского дискурса. Сравнительный анализ медицинских и лингвистических жанров показал, что исследовательская статья и обзорная статья являются универсальными жанрами исследовательского дискурса, так как широко представлены в рассматриваемых областях научного знания.

Медицинский исследовательский дискурс представлен большим количеством жанров, чем лингвистический, что явно указывает на дисциплинарную вариативность. Ключевым жанром исследовательского дискурса является исследовательская статья, поскольку она лидирует среди других жанров как в медицинских, так и в лингвистических научных журналах.

Макроструктура исследовательской статьи является универсальной характеристикой англоязычного исследовательского дискурса. Универсальными разделами исследовательской статьи являются Заголовок, Введение, Методы, Результаты, Обсуждение 
и Заключение. Дисциплинарная вариативность исследовательского дискурса заключается в следующем:

- качественные (синтаксические) и количественные (количество слов) вариации в заголовках;

- наличие стандартизованных или дескриптивных названий разделов статьи;

- композиционно-семантическая обособленность или объединение разделов;

- композиционная детализация (наличие подразделов) внутри разделов;

- использование разных графических средств.

В заключение отметим, что дальнейшее изучение дискурсивно-жанровых характеристик англоязычной исследовательской статьи позволит расширить и углубить наше представление о норме и практике письменного модуса англоязычного академического дискурса.

\section{ЛИТЕРАТУРА}

1. Halliday M. A. K., Strevens P. \& McIntosh A. The linguistic sciences and language teaching. London: Longman, 1964. $215 \mathrm{p}$.

2. Hamp-Lyons L. English for academic purposes // The Cambridge TESOL Guide. Cambridge : Cambridge University Press, 2001. Pp. 126-130.

3. Flowerdew L. Language for specific purposes : English for academic purposes // The Encyclopedia of Applied Linguistics. Oxford: Wiley-Blackwell, 2012. URL: https:// doi.org/10.1002/9781405198431.wbeal0376

4. Bhatia V. K. A generic view of academic discourse // J. Flowerdew (Ed.). Academic Discourse. London : Longman, 2002. Pp. 21-39.

5. Swales J. Research Genres. Explorations and Applications. New York : Cambridge University Press, 2004. $260 \mathrm{p}$.

6. Hyland K. Academic Discourse: English in a Global Context. London and New York : Continuum, 2009. P. 256.

7. Paltridge $B$. Genre analysis and the identification of textual boundaries. Applied Linguistics. 1994. No. 15, 3. Pp. 288-299.

8. Tribble $C$. Corpora and corpus analysis : New windows on academic writing // J. Flowerdew (ed.). Academic Discourse. London : Longman, 2002. Pp. 131-149.

9. Yoon $H$. More than a linguistic reference : The influence of corpus technology on L2 academic writing // Language Learning and Technology. 2008. No. 12. Pp. 31-48.

10. Martin-Martin P. A genre analysis of English and Spanish research paper abstracts in experimental social sciences // English for Specific Purposes. 2003. No. 22. Pp. 25-43.

11. Salager-Meyer F. Scientific publishing in peripheral (a.k.a. developing) countries : Challenges for the future // Journal of English for Academic Purposes. 2008. No. 7(2). Pp. 121-132.

12. Hirano E. Research article introductions in English for specific purposes : A comparison between Brazilian
Portuguese and English // English for Specific Purposes. 2009. No. 28. Pp. 240-250.

13. Кубрякова E. С. Язык и знание. На пути получения знаний о языке : части речи с когнитивной точки зрения. Роль языка в познании мира. М. : Языки славянской культуры, 2004. 556 с.

14. Цурикова Л. В. Проблема естественности дискурса в межкультурной коммуникации. Воронеж : Воронеж. гос. ун-т, 2002. 257 с.

15. Стеблецова А. О. Метапрофессиональный деловой дискурс : типология и национальная специфика. Воронеж : Истоки, 2017. С. 310.

16. Цурикова Л. В., Кузьменко П. Б. Сопоставление содержательного наполнения англоязычных и русскоязычных статей по лингвистике // Культура и текст. АлтГПУ, 2020. С. 144-158.

17. Дементьев В. В. Теория речевых жанров. М. : Знак, 2010. С. 600.

18. Swales J. Genre Analysis : English in Academic and Research Settings. Cambridge : CUP, 1990. P. 288.

19. Bhatia $V$. K. Analysing Genre : Language Use in Professional Settings. London : Longman, 1993. P. 246.

20. Hyland K. Academic discourse // Continuum Companion to Discourse Analysis. London : Continuum, 2011. Pp. 171-184.

21. Flowerdew J. Academic discourse. London : Longman, 2002. $341 \mathrm{p}$.

22. Berkenkotter C. and Huckin T. Genre Knowledge in Disciplinary Communication : Cognition/Culture/Power. Hillsdale, NJ : Lawrence Erlbaum, 1995.

23. Hyland $K$. Hedging in Scientific Research Articles. Amsterdam : John Benjamins, 1998.

24. Hyland $K$. 'As can be seen: Lexical bundles and disciplinary variation' // English for Specific Purposes. 2008. No. 27(1). Pp. 4-21.

25. Basturkmen H. Commenting on results in published research articles and masters dissertations in language teaching // Journal of English for Academic Purposes. 2009. No. 8. Pp. 241-51.

26. Charles $M$. The construction of stance in reporting clauses : a cross-disciplinary study of theses // Applied Linguistics. 2006. No. 27. Pp. 492-518.

27. Bloor $M$. Variations in the method sections of research articles across disciplines : the case of fast and slow text // Issues in EAP writing, research and instruction. Reading : CALS, The University of Reading, 1998. Pp. 84-106.

28. Duszak A. Analyzing digressiveness in Polish academic texts // Culture and Styles of Academic Discourse. Berlin : Mouton de Gruyter, 1997. Pp. 323-341.

29. Connor U. Contrastive rhetoric. Cambridge : Cambridge University Press, 1996. 218 p.

30. Connor $U$. New directions in contrastive rhetoric // TESOL Quarterly. 2002. No. 36. Pp. 493-510.

31. Hyland K. Disciplinary Discourses. Ann Arbor : University of Michigan Press, 2004.

32. Карасик В. И. О категориях дискурса // Языковая личность : социолингвистические и эмотивные аспекты : сб. науч. трудов. Волгоград : Перемена, 1998. С. 185-197. 
33. Стеблецуова А. О., Науменко Ю. Н. Заголовки английских и русских научных статей: дискурсивно-когнитивные особенности // Вестник Моск. гос. лингв. ун-та. Гуманитарные науки. 2019. № 4 (820). С. 161-179.

\section{ИСТОЧНИКИ} applij

1. Applied Linguistics. URL: https://academic.oup.com/

2. Applied Linguistics Research Journal. URL: http:// www.alrjournal.com/

3. Discourse Studies. URL: https://www.researchgate. net/journal/1461-4456_Discourse_Studies

4. British Medical Journal. URL: https:/www.bmj.com/

5. New England Journal of Medicine. URL: https:// www.nejm.org/

\section{REFERENCES}

1. Halliday M. A. K., Strevens P. \& McIntosh A. The linguistic sciences and language teaching. London: Longman, 1994. $215 \mathrm{p}$.

2. Hamp-Lyons L. English for academic purposes. In The Cambridge TESOL Guide. Cambridge: Cambridge University Press, 2001. Pp. 126-130.

3. Flowerdew L. Language for specific purposes: English for academic purposes. In The Encyclopedia of Applied Linguistics. Oxford: Wiley-Blackwell. Available at: https:// doi.org/10.1002/9781405198431.wbea10376

4. Bhatia V. K. A generic view of academic discourse. In J. Flowerdew (Ed.) Academic Discourse, Longman, London, 2002. Pp. 21-39.

5. Swales J. Research Genres. Explorations and Applications. New York: Cambridge University Press, 2004. 304. $260 \mathrm{p}$.

6. Hyland K. Academic Discourse: English in a Global Context. London and New York: Continuum, 2009. 256 p.

7. Paltridge B. Genre analysis and the identification of textual boundaries. In Applied Linguistics. 1994. No. 15, 3. Pp. 288-299.

8. Tribble C. Corpora and corpus analysis: New windows on academic writing. In J. Flowerdew (ed.), Academic Discourse. London: Longman, 2002. Pp. 131-149.

9. Yoon H. More than a linguistic reference: The influence of corpus technology on L2 academic writing. In Language Learning and Technology. 2008. No. 12. Pp. 31-48.

10. Martin-Martin P. A genre analysis of English and Spanish research paper abstracts in experimental social sciences. In English for Specific Purposes. 2003. No. 22. Pp. 25-43.

11. Salager-Meyer F. Scientific publishing in peripheral (a.k.a. developing) countries: Challenges for the future. In Journal of English for Academic Purposes. 2008. No. 7(2). Pp. 121-132.

12. Hirano E. Research article introductions in English for specific purposes: A comparison between Brazilian Portuguese and English. In English for Specific Purposes. 2009. No. 28. Pp. 240-250.
13. Kubryakova E. S. Jazyk i znanie. Na puti polucheniya znanij o yazyke: chasti rechi s kognitivnoj tochki zreniya. Rol'yazyka v poznanii mira [Language and knowledge. Towards gaining knowledge of the language: parts of speech from a cognitive point of view. The role of language in the knowledge of the world] Moscow: Jazyki slavyanskoj kul'tury, 2004. 556 p.

14. Tsurikova L. V. Problema estestvennosti diskursa v mezhkul'turnoj kommunikatsii [The problem of the naturalness of discourse in intercultural communication. Voronezh: Voronezh. gos. un-t, 2002. 257 p.

15. Stebletsova A. O. Metaprofessional'nyj delovoj diskurs: tipologiya i natsional'naya spetsifika [Metaprofessional business discourse: typology and national specificity]. Voronezh: Istoki, 2017. $310 \mathrm{p}$.

16. Tsurikova L. V., Kuz'menko P. B. Sopostavlenie soderzhatel'nogo napolneniya angloyazychnykh i russkoyazychnykh statej po lingvistike [Comparison of the content of English-language and Russian-language articles on linguistics]. Kul'tura i tekst. AltGPU, 2020. Pp. 144-158.

17. Dement'ev V. V. Teoriya rechevykh zhanrov. [Theory of Speech Genres]. Moscow: Znak, 2010. 600 p.

18. Swales J. Genre Analysis: English in Academic and Research Settings. Cambridge: CUP, 1990. 288 p.

19. Bhatia V. K. Analysing Genre: Language Use in Professional Settings. London: Longman, 1993. 246 p.

20. Hyland K. Academic discourse. In Continuum Companion to Discourse Analysis. London: Continuum, 2011. Pp. 171-184.

21. Flowerdew J. Academic discourse. London, England: Longman, 2002. $341 \mathrm{p}$.

22. Berkenkotter C. and Huckin T. Genre Knowledge in Disciplinary Communication: Cognition/Culture/Power. Hillsdale, NJ: Lawrence Erlbaum, 1995.

23. Hyland K. Hedging in Scientific Research Articles. Amsterdam: John Benjamins, 1998.

24. Hyland K. 'As can be seen: Lexical bundles and disciplinary variation'. In English for Specific Purposes. 2008. No. 27(1). Pp. 4-21.

25. Basturkmen H. Commenting on results in published research articles and masters dissertations in language teaching. In Journal of English for Academic Purposes. 2009. No. 8. Pp. 241-251.

26. Charles $\mathrm{M}$. The construction of stance in reporting clauses: a cross-disciplinary study of theses. In Applied Linguistics. 2006. No. 27. Pp. 492-518.

27. Bloor M. Variations in the method sections of research articles across disciplines: the case of fast and slow text. In Issues in EAP writing, research and instruction. Reading: CALS, The University of Reading, 1998. Pp. 84106.

28. Duszak A. Analyzing digressiveness in Polish academic texts. In Culture and Styles of Academic Discourse. Berlin: Mouton de Gruyter, 1997. Pp. 323-341.

29. Connor U. Contrastive rhetoric. Cambridge, England: Cambridge University Press, 1996. 218 p. 
30. Connor U. New directions in contrastive rhetoric. In TESOL Quarterly. 2002. No. 36. Pp. 493-510.

31. Hyland K. Disciplinary Discourses. Ann Arbor: University of Michigan Press, 2004.

32. Karasik V. I. O kategoriyakh diskursa. [On the categories of discourse]. In Yazykovaya lichnost': sotsiolingvisticheskie i ehmotivnye aspekty: Sb. nauch. tr. Volgograd: Peremena, 1998. Pp. 185-197.

33. Stebletsova A. O., Naumenko Y. N. Zagolovki anglijskikh i russkikh nauchnykh statej: diskursivno-kognitivnye osobennosti. [Headings of English and Russian research articles: discursive-cognitive features]. In Vestnik Moskovskogo gosudarstvennogo lingvisticheskogo uni-

Воронежский государственный университет

Вахтерова Е. В., аспирант кафедры теоретической и прикладной лингвистики

E-mail: elena91vahterova@mail.ru

Борискина О. О., доктор филологических наук, декан факультета романо-германской филологии

E-mail: boriskinatipl@mail.ru

Воронежский государственный медицинский университет имени Н. Н. Бурденко

Стеблецова А. О., доктор филологических наук

E-mail: annastebl@vrngmu.ru

Поступила в редакичию 30 апреля 2020 г.

Принята к публикаџии 15 июня 2020 г.

\section{Для циитирования:}

Вахтерова Е. В., Борискина О. О., Стеблецчова А. О. Исследовательский дискурс: жанровые универсалии и дисциплинарная специфика научных статей // Вестник Воронежского государственного университета. Серия: Лингвистика и межкультурная коммуникация. 2020. № 3. C. 69-78. DOI: https://doi.org/10.17308/lic.2020.3/2935 versiteta. Gumanitarnye nauki. 2019. No. 4 (820). Pp. 161-179.

\section{SOURCES}

1. Applied Linguistics. Available at: https://academic. oup.com/applij

2. Applied Linguistics Research Journal. Available at: http://www.alrjournal.com/

3. Discourse Studies. Available at: https:/www.researchgate.net/journal/1461-4456_Discourse_Studies

4. British Medical Journal. Available at: https://www. bmj.com/

5. New England Journal of Medicine. Available at: https://www.nejm.org/

Voronezh State University

Vakhterova E. V., Post-graduate Student of the Theoretical and Applied Linguistics Department

E-mail: elena91vahterova@mail.ru

Boriskina O. O., Doctor of Philology, Dean of the Romance and Germanic Philology Faculty

E-mail: boriskinatipl@mail.ru

Voronezh N. N. Burdenko State Medical University

Stebletsova A. O., Doctor of Philology

E-mail:annastebl@vrngmu.ru

Received: 30 April 2020

Accepted: 15 June 2020

\section{For citation:}

Vakhterova E. V., Boriskina O. O., Stebletsova A. O. Research discourse: genre universals and disciplinary specifics of research papers. Proceedings of Voronezh State University. Series: Linguistics and Intercultural Communication. 2020. No. 3. Pp.69-78. DOI: https://doi.org/10.17308/ lic. $2020.3 / 2935$ 